\title{
ANAESTHETIC MANAGEMENT OF A POLYMYOSITIS PATIENT FOR ABDOMINAL MASS EXCISION
}

Sivakumar Pillai ${ }^{1}$, Jampala Karthikeya², Sabari Jayaram³ ${ }^{3}$, Mopuru Pradeep ${ }^{4}$

\section{HOW TO CITE THIS ARTICLE:}

Sivakumar Pillai, Jampala Karthikeya, Sabari Jayaram, Mopuru Pradeep. "Anaesthetic Management of A Polymyositis Patient for Abdominal Mass Excision". Journal of Evolution of Medical and Dental Sciences 2015; Vol. 4, Issue 60, July 27; Page: 10573-10576, DOI: 10.14260/jemds/2015/1526

ABSTRACT: Polymyositis is a sub-acute inflammatory myopathy affecting adults. It can be associated as paraneoplastic disease with a progressive symmetrical weakness. Pharyngeal neck and flexor muscles may be involved leading to dysphagia, difficulty in neck holding and it may involve the respiratory muscles.

KEYWORDS: Polymyositis, Musclerelaxants, Ventilatorsupport, Steroids, Epiduralanalgesia.

INTRODUCTION: Polymyosistis is a multisystem disease of unknown etiology that manifests as inflammatory myopathies. In these patients management of anaesthesia there is always vulnerability to pulmonary aspiration.(1) There is a concern that these patients display abnormal response to muscle relaxants.(1) Multisystem concerns and their anaesthetic implications have been discussed in this case report.

CASE REPORT: A 60 yrs old female polymyositis patient presented with lump abdomen, with history of previous surgery for caovary and cabreast 6yrs back. She had underwent chemotherapy after the surgery. She has history of polymyositis mainly involving the lower limb muscles. Patient had increased weakness, paraparesis and was bedridden for the last three weeks. She was started on high dose steroids (Prednisolone 40mg OD) and was gradually tapered off. On evaluation she had increased tumor markers with significant elevation in CEA. CT abdomen showed suspicious mass involving colon. She was posted for laparotomy. Electromyography is performed on the right side which revealed increased spontaneous fibrillations, complex repetitive discharges, and intermittent polyphasic short bursts.

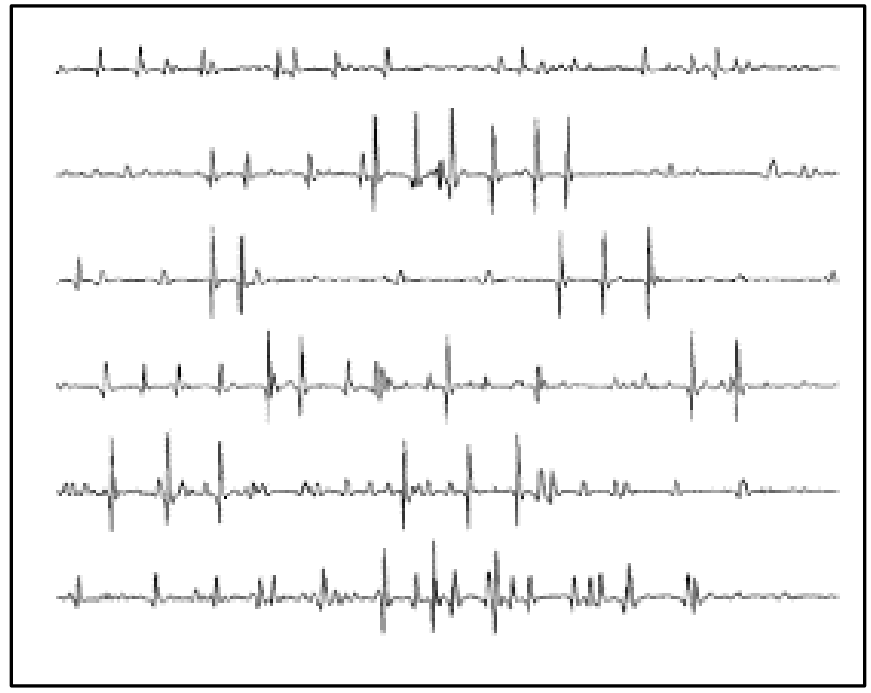


Polymyositis being a rare disease, limited information relating to anaesthetic management is available.

ANAESTHETIC MANAGEMENT: The pros and cons of different anaesthetic techniques were discussed with the bystanders and consent (Highrisk, postopventilator) was obtained. She was premedicated with RanitidineIV and Metoclopramide10mgIV. Sedative medications were avoided. IVFluid0.9\%NS was started and she was shifted to OT.

Pre Induction Monitors: ECG, NIBP, SPO2.

Post Induction monitors: IBP, CVP, ECG, SPO2, UO, ETCO2.

Under strict asepsis and after giving local anaesthesia Epidural catheter was inserted at T11T12 interspace. She was induced with Inj Propofol 100mg IV, Inj Fentanyl 100mcg IV, deepened with inhalational sevo 2\%, Inj Atracurium 25mg IV was given and patient was intubated with ETTID $7.5 \mathrm{~mm}$, under cricoids pressure. Anaesthesia was maintained with 02, sevo and nitrous along with Epidural LA $0.125 \%$ Bupivacaine+Injfentany $11 \mathrm{mcg} / \mathrm{ml}$ till the end of surgery. Intraoperatively patient was stable, ABG was normal.

Volatile was stopped at the end of surgery, and patient was extubated fully conscious after reflexes were obtained. Postoperatively analgesia was maintained with $0.0625 \%$ Bupivacaine Epidural infusion. The epidural catheter was removed on day 5. She received full muscle power, she was ambulatory and was discharged on day 7.

DISCUSSION: Polymyositis is a sub-acute inflammatory myopathy affecting adults. It can be associated as paraneoplastic disease even though dermatomyositis is more common.(2) It presents as a progressive symmetrical weakness. Pharyngeal neck and flexor muscles may be involved leading to dysphagia, difficulty in neck holding and it may involve the respiratory muscles although rarely seen. It is more commonly associated with connective tissue disorders than paraneoplastic syndromes. Other problems other than muscle weakness include cardiac disturbances like AV conduction defects, Tachyarrythmias, Dilated cardiomyopathy. It is also associated with EMG and skeletal muscle enzyme abnormalities. ${ }^{(3)}$

\section{For Anaesthesia Major Concerns Include:}

1. Pulmonary problems due to pharyngeal, diaphragmatic muscle weakness, aspiration, lung fibrosis and infective complications due to long term steroids.

2. Cardiomyopathy.

3. Delayed recovery from muscle relaxants.

4. Implications in regional anaesthesia in a patient with muscle weakness.

5. Immunosupressants like azathioprine methotextrate. $(4,5)$

In literature as well as previous studies epidurals with local anaesthetic-opoid mixture have been successfully used without any worsening of muscle weakness.(5) In our case we used thoracic epidural with ETT and inhalational agent. Though epidural can be used alone for the laparotomies but concerning the need for repeated laparotomies in these patients we chose to use GA with 
epidural as choice of anaesthesia. IBP monitoring was done as there is always a chance of hemodynamic compromise, arrhythmias, cardiomyopathies. Our patient was stable in the intraoperative period.

TIVA alone can be used with propofol and remifentanyl though volatile agents are not contraindicated in our patient.(6) But patients with mitochondrial diseases and congenital myopathies may have risk of malignant hyperpyrexia in which case volatile usage for long duration is a concern. Some authors have used Nueromuscular blockers like Atracurium carefully titrated using peripheral Nueromuscular monitors with good safety rewards. Scoline also have been used successfully for the initial dose. The advantage of epidural for the role of postop analgesia can't be substituted with any other drugs. Risk of DVT can also be reduced with epidurals.(6)

CONCLUSION: Polymyositis and other myopathies can be seen in cancer patients presenting for surgeries. So the anaesthetic implications need to be kept in mind while planning anaesthesia to prevent postoperative complications.

Well planned anaesthesia and judicious use of drugs can help in giving safe anaesthesia in these patients.

\section{REFERENCES:}

1. Dalakas MC. Polymyositis, dermatomyositis, Harrison's principles of internal medicine. 17th ed. United States of America: McGraw-Hill; 2008. p. 2696-702.

2. Schwartz JJ. Skin and musculoskeletal diseases. In: Hines RL, Marschall KE, editors. Stoelting's Anesthesia and Co-existing Disease. 5th ed. Philadelphia: Churchill Livingstone; 2008. p. 43767.

3. Anaesthetic management for laparoscopic cholecystectomy in two patients with biopsy proven polymyositis. Shikha S, Lakshmi J, Nitin S, Jayashree S: Indian J Anaesth 2007, 51: 43-46.

4. Anesthetic management for colon resection in a patient with polymyositis. Fujita A, Okutani R, FuK The Japaneese Journal of Anaesthesiology[1996, 45(3): 334-336].

5. Ohta M, Nishikawa N, Kida H, Miyao S: Anesthetic management of two patients with polymyositis. Masui 2000, 49:1371-1373.

6. Fathi M, Lundberg IE, Tornling G: Pulmonary complications of Polymyositis and Dermatomyositis. Semin Respir Crit care Med 2007, 28: 451-458. 


\section{CASE REPORT}

\section{AUTHORS:}

1. Sivakumar Pillai

2. Jampala Karthikeya

3. Sabari Jayaram

4. Mopuru Pradeep

\section{PARTICULARS OF CONTRIBUTORS:}

1. Assistant Professor, Department of Anaesthesiology, Sree Gokulam Medcial College.

2. Junior Resident, Department of Anaesthesiology, Sree Gokulam Medcial College.

FINANCIAL OR OTHER

COMPETING INTERESTS: None
3. Junior Resident, Department of Anaesthesiology, Sree Gokulam Medcial College.

4. Junior Resident, Department of Anaesthesiology, Sree Gokulam Medcial College.

\section{NAME ADDRESS EMAIL ID OF THE CORRESPONDING AUTHOR:}

Dr. Shivakumar Pillai,

7h, Heera Apartment, Kesavadasa Puram, Trivandrum-695004.

E-mail: ssivapillai@gmail.com

Date of Submission: 22/06/2015.

Date of Peer Review: 23/06/2015.

Date of Acceptance: 09/07/2015.

Date of Publishing: 27/07/2015. 